\title{
Direct Evidence of Astrocytic Modulation in the Development of Rewarding Effects Induced by Drugs of Abuse
}

\author{
Minoru Narita*,', Mayumi Miyatake', Michiko Narita', Masahiro Shibasaki', Keiko Shindo', \\ Atsushi Nakamura', Naoko Kuzumaki', Yasuyuki Nagumo' and Tsutomu Suzuki*,' \\ 'Department of Toxicology, Hoshi University School of Pharmacy and Pharmaceutical Sciences, Tokyo, Japan
}

\begin{abstract}
Long-term exposure to pyschostimulants and opioids induced neuronal plasticity. Accumulating evidence suggests that astrocytes actively participate in synaptic plasticity. We show here that a glial modulator propentofylline (PPF) dramatically diminished the activation of astrocytes induced by drugs of abuse, such as methamphetamine (METH) and morphine (MRP). In vivo treatment with PPF also suppressed both METH- and MRP-induced rewarding effects. On the other hand, intra-nucleus accumbens (N.Acc.) administration of astrocyte-conditioned medium (ACM) aggravated the development of rewarding effects induced by METH and MRP via the Janus kinase/signal transducers and activators of transcription (Jak/STAT) pathway, which modulates astrogliosis and/or astrogliogenesis. Furthermore, ACM, but not METH itself, clearly induced the differentiation of multipotent neuronal stem cells into glial fibrillary acidic protein-positive astrocytes, and this effect was reversed by cotreatment with the Jak/STAT inhibitor AG490. Intra-cingulate cortex (CG) administration of ACM also enhanced the rewarding effect induced by METH and MRP. In contrast to ACM, intra-N.Acc. administration of microglia-conditioned medium failed to affect the rewarding effects of METH and MRP in mice. These findings suggest that astrocyte-, but not microglia-, related soluble factors could amplify the development of rewarding effect of METH and MRP in the N.Acc. and CG. The present study provides direct evidence that astrocytes may, at least in part, contribute to the synaptic plasticity induced by drugs of abuse during the development of rewarding effects induced by psychostimulants and opioids.

Neuropsychopharmacology (2006) 3 I, 2476-2488. doi: I 0. I038/sj.npp. I 30 I007; published online I I January 2006
\end{abstract}

Keywords: astrocyte; methamphetamine; morphine; rewarding effect; nucleus accumbens; cingulate cortex

\section{INTRODUCTION}

Studies of human addicts and behavioral studies in rodent models of addiction indicate that key behavioral abnormalities associated with addiction are extremely long lived. Drugs of abuse are chemically divergent molecules with very different initial activities. However, many pharmacological and biochemical findings support the idea that longterm exposure to psychostimulants induces neuronal plasticity (Nestler, 2001; Hyman and Malenka, 2001; Self, 2004). Prominent amount these actions is the activation of the mesolimbic dopamine system (Shippenberg et al, 1992; Wise and Hoffman, 1992; De Vries and Shippenberg, 2002); this activation involves increased firing of dopamine neurons in the ventral tegmental area (VTA) of the midbrain and a subsequent increase of dopamine released into the nucleus accumbens (N.Acc.).

\footnotetext{
*Correspondence: Dr M Narita and Dr T Suzuki, Department of Toxicology, Hoshi University School of Pharmacy and Pharmaceutical Sciences, 2-4-4I Ebara, Shinagawaku, Tokyo I42-850I, Japan, Tel/Fax: + 8 I 35498 5627, E-mails: narita@hoshi.ac.jp and suzuki@hoshi.ac.jp Received 15 August 2005; revised 7 November 2005; accepted 9 November 2005

Online publication: II November 2005 at http://www.acnp.org/ citations/Npp | | | | 050505 | 7/default.pdf
}

These are two categories of cells in the central nervous system (CNS); neurons and adjacent glial cells including astrocytes, microglia and oligodendrocytes. Over the past decade, an increasing number of observations have progressively challenged the classical view that glial cells only serve passive supportive function in the CNS. Astrocytes have important physiological properties as they relate to CNS homeostasis. Moreover, astrocytes affect neuronal function by the release of neurotransmitters and neurotrophic factors, guide neuronal development, contribute to the metabolism of neurotransmitters, and regulate extracellular $\mathrm{pH}$ and $\mathrm{K}^{+}$levels (Vesce et al, 2001; Bohn, 2004; Fellin and Carmignoto, 2004). Astrocytes undergo a process of proliferation, morphological changes, and enhancement of glial fibrillary acidic protein (GFAP) expression, termed the activation of astrocytes or astrogliosis (Raivich et al, 1999). Moreover, astrocytes are immunocompetent cells in the CNS. Both in vitro and in vivo studies have documented the ability of astrocytes to produce interleukin- $1,-6$, and -10 ; interferon- $\alpha$, and $-\beta$; colony-stimulating factors GM-CSF, M-CSF, and G-CSF; TNF- $\alpha$; TGF- $\beta$; and chemokines (Dong and Benveniste, 2001). Accumulating evidence suggests that astrocytes may actively participate in synaptic plasticity (Ullian et al, 2004; Abrous et al, 2005). 
It has been documented that repeated amphetamine treatment results in the increased astrocytic expression of basic fibroblast growth factor in the VTA and substantia nigra compacta, which is necessary for the development of sensitization to amphetamine (Flores et al, 2000). It has also been reported that GFAP expression is increased in the VTA and hippocampus following relatively short-term withdrawal subsequent to cocaine exposure (Bowers and Kalivas, 2003). We previously reported that the levels of GFAP in the mouse N.Acc. and cingulate cortex (CG) were clearly increased by chronic in vivo administration of methamphetamine (METH) (Narita et al, 2005a). These data raise the possibility that astrocytes contribute to the synaptic plasticity during the development of rewarding effects induced by psychostimulants. However, little is known about direct action of astrocytes on the development of rewarding effects induced by drugs of abuse. The present study was then undertaken to clarify the role of astrocytes in the development of rewarding effects induced by METH and morphine (MRP).

\section{MATERIALS AND METHODS}

The present studies were conducted in accordance with the Guide for Care and Use of Laboratory Animals adopted by the Committee on Care and Use of Laboratory Animals of Hoshi University School of Pharmacy and Pharmaceutical Sciences, which is accredited by the Ministry of Education, Culture, Sports, Science, and Technology of Japan.

\section{Tissue Processing}

Purified cortical astrocytes were grown as follows: cerebral cortices were obtained from newborn ICR mice (Tokyo Laboratory Animals Science Co. Ltd, Tokyo, Japan), minced, and treated with trypsin $(0.025 \%$, Invitrogen Co., Carlsbad, CA, USA) dissolved in phosphate-buffered saline (PBS) solution containing 0.02\% L-cysteine (Sigma-Aldrich Co., St Louis, MO, USA) monohydrate, $0.5 \%$ glucose (Wako Pure Chemicals Ind. Ltd, Osaka, Japan) and $0.02 \%$ bovine serum albumin (Wako Pure Chemicals Ind. Ltd). After enzyme treatment at $37^{\circ} \mathrm{C}$ for $15 \mathrm{~min}$, cells were dispersed by gentle agitation through a pipette and plated on a flask. At 1 week after seeding in Dulbecco's modified Eagle's medium (DMEM, Invitrogen Co.) supplemented with 5\% fetal bovine serum (FBS, Invitrogen Co.), 5\% heatinactivated $\left(56^{\circ} \mathrm{C}, 30 \mathrm{~min}\right)$ horse serum (HS, Invitrogen Co.), $10 \mathrm{U} / \mathrm{ml}$ penicillin and $10 \mu \mathrm{g} / \mathrm{ml}$ streptomycin in a humidified atmosphere of $95 \%$ air and $5 \% \mathrm{CO}_{2}$ at $37^{\circ} \mathrm{C}$, the flask was shaken for $12 \mathrm{~h}$ at $37^{\circ} \mathrm{C}$ to remove nonastrocytic cells. The cells were seeded at a density of $1 \times 10^{5} \mathrm{cells} / \mathrm{cm}^{3}$. The cells were maintained for 3-10 days in DMEM supplemented with $5 \% \mathrm{FBS}, 5 \% \mathrm{HS}, 10 \mathrm{U} / \mathrm{ml}$ penicillin, and $10 \mu \mathrm{g} / \mathrm{ml}$ streptomycin in a humidified atmosphere of $95 \%$ air and $5 \% \mathrm{CO}_{2}$ at $37^{\circ} \mathrm{C}$.

To prepare astrocyte-conditioned medium (ACM), astrocytes were grown to confluence. Cells were washed once with DMEM and then covered with an equal volume of serum-free medium for $24 \mathrm{~h}$ at $37^{\circ} \mathrm{C}$ and $5 \% \mathrm{CO}_{2}$ in the presence of the indicated treatments. The supernatant was collected 1 day after changing to serum-free medium culture and centrifuged for $20 \mathrm{~min}$ at $1000 \mathrm{~g}$. The final supernatant was used as ACM.

Purified cortical microglia were grown as follows: cerebral cortices were obtained from newborn ICR mice (Tokyo Laboratory Animals Science Co. Ltd), minced, and treated with trypsin $(0.025 \%$, Invitrogen Co.) dissolved in phosphate-buffered saline (PBS) solution containing $0.02 \%$ L-cysteine (Sigma-Aldrich Co.) monohydrate, $0.5 \%$ glucose (Wako Pure Chemicals Ind. Ltd) and $0.02 \%$ bovine serum albumin (Wako Pure Chemicals Ind. Ltd). After enzyme treatment at $37^{\circ} \mathrm{C}$ for $15 \mathrm{~min}$, cells were dispersed by gentle agitation through a pipette and plated on a flask with DMEM supplemented with 5\% FBS, 5\% HS, $10 \mathrm{U} / \mathrm{ml}$ penicillin, and $10 \mu \mathrm{g} / \mathrm{ml}$ streptomycin in a humidified atmosphere of $95 \%$ air and $5 \% \mathrm{CO}_{2}$ at $37^{\circ} \mathrm{C}$. The cultured medium was exchanged to new medium every 3 days. About 9 days after seeding, the flask was shaken for $2 \mathrm{~min}$ to remove microglia. A cell suspension were collected and centrifuged $(20 \mathrm{~min}, 3000 \mathrm{~g})$. The cells were seeded at a density of $1 \times 10^{5}$ cells $/ \mathrm{cm}^{3}$. The cells were maintained for 3 days in DMEM supplemented with 5\% FBS, 5\% HS, $10 \mathrm{U} / \mathrm{ml}$ penicillin and $10 \mu \mathrm{g} / \mathrm{ml}$ streptomycin in a humidified atmosphere of $95 \%$ air and $5 \% \mathrm{CO}_{2}$ at $37^{\circ} \mathrm{C}$.

To prepare microglia-conditioned medium (MCM), microglia were grown to confluence. Cells were washed once with DMEM and then covered with an equal volume of serum-free medium for $24 \mathrm{~h}$ at $37^{\circ} \mathrm{C}$ and $5 \% \mathrm{CO}_{2}$ in the presence of the indicated treatments. The supernatant was collected 1 day after changing to the serum-free medium culture and centrifuged $(20 \mathrm{~min}, 3000 \mathrm{~g})$. The final supernatant was used as MCM.

Cortical neuron/glia cocultures were grown as follows; cerebral cortex was obtained from newborn ICR mice (Tokyo Laboratory Animals Science Science Co. Ltd), minced, and treated with papain $(9 \mathrm{U} / \mathrm{ml}$, Worthington Biochemical, Lakewood, NJ, USA) dissolved in PBS solution containing $0.02 \%$ L-cysteine monohydrate, $0.5 \%$ glucose, and $0.02 \%$ bovine serum albumin. After enzyme treatment at $37^{\circ} \mathrm{C}$ for $15 \mathrm{~min}$, cells were seeded at a density of $2 \times 10^{6}$ cells $/ \mathrm{cm}^{3}$. The cells were maintained for 7 days in DMEM supplemented with $10 \%$ FBS, $10 \mathrm{U} / \mathrm{ml}$ penicillin and $10 \mu \mathrm{g} / \mathrm{ml}$ streptomycin. On day 8 , the cells were treated with drugs.

\section{Drug Treatment and Immunohistochemistry}

We previously reported that in vitro 3 days treatment with METH hydrochloride (METH, $10 \mu \mathrm{M}$, Dainippon Pharmaceutical Co. Ltd, Osaka, Japan), or morphine hydrochloride (MRP, $10 \mu \mathrm{M}$, Sankyo Co. Ltd, Tokyo, Japan) caused the activation of astrocytes without neuronal cell death in mouse cortical neuron/glia cocultures (Narita et al, 2005a). According to this report, mouse cortical neuron/ glia cocultures were treated with either normal medium, METH $(10 \mu \mathrm{M}), \quad \mathrm{METH}+3$-methyl-1-(5-oxohexyl)-7-propylxanthine (propentofylline: $\mathrm{PPF}, 1,3 \mu \mathrm{M}$, Sigma-Aldrich Co.), MRP $(10 \mu \mathrm{M})$ or MRP $(10 \mu \mathrm{M})+\operatorname{PPF}(1,3 \mu \mathrm{M})$ for 3 days. To explore the effect of astrocyte-related soluble factors, mouse purified cortical astrocytes were treated with either DMEM, ACM, ACM collected from METH (10 and $100 \mu \mathrm{M}, 3$ days)-treated astrocytes (METH10-ACM and METH100-ACM) or ACM collected from MRP (10 and 
$100 \mu \mathrm{M}, 3$ days)-treated astrocytes (MRP10-ACM and MRP100-ACM) for 1 day. Mouse purified cortical microglia were treated with either normal medium, METH $(1-100 \mu \mathrm{M})$ or MRP $(1-100 \mu \mathrm{M})$ for 3 days. The cells were then identified by immunofluorescence using mouse anti-GFAP antibody (1:1000, Chemicon, International Inc.) or rat antiOX42 antibody (1:250, Serotec Ltd, Oxford, UK) followed by incubation with Alexa 488-conjugated goat anti-mouse IgG (1:4000) or with Alexa 488-conjugated goat anti-rat IgG (1:4000). Images were collected using a Radiance 2000 laserscanning microscope (BioRad, Richmond, CA, USA). The experiments were repeatedly performed by, at least, three independent culture preparations.

The intensity of GFAP-like immunoreactivity was measured with a computer-assisted system (NIH Image). The upper and lower threshold intensity ranges were adjusted to encompass and match the immunoreactivity to provide an image with immunoreactive material appearing in black pixels, and nonimmunoreactive material as white pixels. The area and intensity of pixels within the threshold value representing immunoreactivity were calculated. We randomly chose 10 areas $(80 \times 80$ pixels $)$ for calculation of GFAP-like immunoreactivity in each image $(512 \times 512$ pixels). The intensity of GFAP-like immunoreactivity was expressed as a percent increase (mean \pm SEM) with respect to that in control cells.

\section{Surgery and Microinjection}

Male ICR mice weighing 25-30 g were obtained from Tokyo Laboratory Animals Science Co. Animals were housed in a room maintained at $22 \pm 1{ }^{\circ} \mathrm{C}$ with a $12 \mathrm{~h}$ light-dark cycle. Food and water were available ad libitum.

After 3 days of habituation to the main animal colony, all mice were anesthetized with sodium pentobarbital (70 $\mathrm{mg} / \mathrm{kg}$, i.p.). The anesthetized animals were placed in a stereotaxic apparatus (Kopf Instruments, CA, USA). The skull was exposed and a small hole was made using a dental drill. An infusion cannula (D-1-6-02, Eicom Co., Kyoto, Japan) was positioned into the nucleus accumbens (N.Acc.: from bregma: anterior $+1.5 \mathrm{~mm}$, lateral $-0.9 \mathrm{~mm}$, ventral $-4.6 \mathrm{~mm}$ ), cingulate cortex (CG: from bregma: anterior $+1.0 \mathrm{~mm}$, lateral $-0.3 \mathrm{~mm}$, ventral $-1.4 \mathrm{~mm}$ ) or corpus striatum (CPu: from bregma: $+1.5 \mathrm{~mm}$, lateral $-1.3 \mathrm{~mm}$, ventral $-3.5 \mathrm{~mm}$ ) according to the atlas of Paxinos and Franklin (1997). The animals were injected with either DMEM, ACM, ACM + AG490 (0.1 nmol, Calbiochem-Novabiochem Co., La Jolla, CA, USA), DMEM-AG490 (0.1 nmol), METH10-ACM, or MCM in a volume of $100 \mathrm{nl} / \mathrm{mouse}$ into the N.Acc. via the infusion cannula using a Hamilton syringe at an infusion rate of $10 \mathrm{nl} / \mathrm{min}$. Other groups of animals were injected with DMEM or ACM in a volume of $100 \mathrm{nl} / \mathrm{mouse}$ into the CG via the infusion cannula using a Hamilton syringe at an infusion rate of $10 \mathrm{nl} / \mathrm{min}$. These mice were returned to their home cages after microinjection. At 1 day after microinjection, mice were used for the behavioral study.

\section{Place Conditioning}

The place-conditioning procedure is used to evaluate the motivation properties, such as rewarding or aversive effects, of drugs in animals (Suzuki et al, 1991). Place conditioning studies were conducted using an apparatus consisting of a shuttle box $\left(15 \times 30 \times 15 \mathrm{~cm}^{3}, w \times l \times h\right)$, which was made of acrylic resin board and divided into two equal-sized compartments. One compartment was white with a textured floor and the other was black with a smooth floor to create equally inviting compartments. The conditioning place preference schedule consisted of three phases (preconditioning test, conditioning, and postconditioning test).

To examine the effect of microinjection with ACM and MCM in the rewarding effects induced by METH and MRP, microinjection of either DMEM, ACM, DMEM + AG490 (0.1 nmol), ACM + AG490 (0.1 nmol), METH10-ACM, or MCM was performed 1 day before the preconditioning test.

The preconditioning test was performed as follows: the partition separating the two compartments was raised to $7 \mathrm{~cm}$ above the floor, a neutral platform was inserted along the seam separating the compartments, and mice that had not been treated with either drugs or saline were then placed on the platform. The time spent in each compartment during a 900 -s session was then recorded automatically using an infrared beam sensor (KN-80, Natsume Seisakusyo Co. Ltd, Tokyo, Japan). We previously reported that chronic treatment with METH $(1 \mathrm{mg} / \mathrm{kg}$, subcutaneous (s.c.)), (Miyatake et al, 2005) or MRP ( $5 \mathrm{mg} / \mathrm{kg}$, s.c.) (Narita et al, 2005b) produced a significant preference for drugassociated place in the conditioned place preference. According to previous reports, conditioning sessions (three for METH or MRP: hree for saline) were started next day after preconditioning test and conducted once daily for 6 days. Immediately after s.c. injection of either METH $(0.0625,0.125,0.25,0.5$, or $1 \mathrm{mg} / \mathrm{kg}$, s.c.) or $\operatorname{MRP}(1,1.7,3,5$, or $5.6 \mathrm{mg} / \mathrm{kg}$, s.c.); these animals were placed in the compartment opposite that in which they had spent the most time in the preconditioning test, for $1 \mathrm{~h}$. On the day after the final conditioning session, these animals were placed in the test apparatus without any confinements, and then the relative amount of time spent in these compartments was measured (postconditioning). The preference for drug-paired place was shown as mean difference between time spent during the postconditioning and preconditioning tests. Each preference score represents the mean \pm SEM of 7-8 mice.

\section{Differentiation Experiments}

MEB5 (IFO50472, the Japanese Cancer Research Resources Bank) was used as multipotent neural stem cells (NSCs). MEB5 is a multipotent stem cell line that can differentiate into neurons, astrocytes, and oligodendrocytes. The cells were plated in uncoated plastic tissue flasks and maintained at $37^{\circ} \mathrm{C}$ and $5 \% \mathrm{CO}_{2}$. The cells were cultured in serum-free medium: DMEM with $4500 \mathrm{mg} / \mathrm{l}$ glucose, $5 \mu \mathrm{g} / \mathrm{ml}$ insulin, $10 \mathrm{ng} / \mathrm{ml} \mathrm{EGF}, 50 \mu \mathrm{g} / \mathrm{ml}$ transferrin, $10 \mathrm{ng} / \mathrm{ml}$ biotin, and $30 \mathrm{nM} \mathrm{Na} \mathrm{NaO}_{3}$. EGF $(10 \mathrm{ng} / \mathrm{ml})$ was used to keep the cultures proliferating. For differentiation experiments, approximately 10 neurospheres of the same size were plated onto $10 \mu \mathrm{g} / \mathrm{ml}$ laminin-coated glass slides and $400 \mu \mathrm{l}$ of serum-free medium with $10 \mathrm{ng} / \mathrm{ml}$ EGF was then added to each well. To determine whether ACM or METH could induce astrocytic differentiation from NSCs, NSCs were exposed to medium containing, ACM, ACM + AG490 
$(1 \mu \mathrm{M})$, or METH $(10 \mu \mathrm{M})$ for 5 days. The medium was replaced with fresh medium every 2 days. At 10 days after drug treatment, these cells were washed in PBS, and fixed in $4 \%$ paraformaldehyde in phosphate buffer at $\mathrm{pH} 7.4$ and room temperature for $30 \mathrm{~min}$. Thereafter, these cells were stained for GFAP.

Astrocytes with processes longer than their perinuclear diameters were defined as stellate cells according to the criteria used by Kimelberg et al, (1978) and Shao et al (1994). The experiments were repeatedly performed by, at least, three independent astrocyte culture preparations. The percentage of stellate cells in each experimental condition was expressed as a percent increase (mean \pm SEM) with respect to that in control cells.

\section{Cytokine Array}

To assay the components of astrocyte-released solved factors, we used RayBio ${ }^{\mathrm{TM}}$ Mouse Cytokine Array (RayBiotech Inc. Norcross, GA, USA). According to the manufacture's protocol, either DMEM, ACM, or METH10-ACM was incubated with RayBio $^{\mathrm{TM}}$ Mouse Cytokine Array membranes, which were conjugated with anticytokine antibodies. After this incubation, membranes were exposed to $\mathrm{X}$-ray film. Film autoradiograms were analyzed and quantified by computer-assisted densitometry using an NIH Image.

\section{Statistical Analysis}

The data of GFAP-like immunoreactivity, astrocyte differentiation and cytokine assay are presented as the mean (percent of control) \pm SEM. The statistical significance of differences between the groups were assessed by one-way ANOVA with Student's $t$-test.

Conditioning scores for each mouse are obtained by subtracting the cumulative time (s) spent in the salinepaired side from that in the drug-paired side, are expressed as means \pm SEM. A statistical analysis for place conditioning study was performed using one-way ANOVA followed by Bonferroni/Dunnett's test or Student's $t$-test (for two-paired comparison).

\section{RESULTS}

\section{The Effects of Glial Modulator PPF}

We previously reported that in vitro treatment of mouse cortical neuron/glia cocultures with either METH $(10 \mu \mathrm{M})$ or MRP $(10 \mu \mathrm{M})$ for 3 days caused the activation of astrocytes, as detected by a stellate morphology and an increase in the levels of GFAP with no neuronal cell death (Narita et al, 2005a). On the other hand, MRP $(10 \mu \mathrm{M})$, but not METH $(10 \mu \mathrm{M})$ failed to induce the activation of astrocytes in mouse-purified cortical astrocytes. In the present study, we used mouse cortical neuron/glia cocultures to confirm the effect of PPF, which is known to modulate glial activity under pathological conditions (Sweitzer et al, 2001; Raghavendra et al, 2004) in the activation of astrocytes induced by METH and MRP. The activation of astrocytes induced by either METH or MRP was dramatically diminished by treatment with PPF (Figure 1a and b).

In the conditioned place preference paradigm, which has been widely used to measure the rewarding properties of psychostimulants, rodents show a preference for environmental stimuli that have been associated with systemic injection of METH or MRP. We next investigated the effect of PPF on the respective rewarding effects of METH and MRP in mice using the conditioned place preference paradigm. Mice conditioned with METH (1 mg/kg, s.c.) or MRP (5 mg/kg, s.c.) exhibited a significant preference for the drug-associated place $(23.8 \pm 17.9 \mathrm{~s}$ for saline-saline, $163.8 \pm 22.0 \mathrm{~s}$ for saline- $1 \mathrm{mg} / \mathrm{kg} \mathrm{METH}$; $p<0.001 v s$ saline-saline, $118.9 \pm 30.5 \mathrm{~s}$ for saline $-5 \mathrm{mg} / \mathrm{kg}$ MRP; $p<0.01$ vs saline-saline, Figure 1c). PPF $(3 \mathrm{mg} / \mathrm{kg}$, i.p.) alone did not induce either significant place preference or place aversion in mice $(-3.0 \pm 22.1 \mathrm{~s})$. Under these conditions, the significant place preference produced by either METH or MPR was suppressed by treatment with $\operatorname{PPF}\left(\mathrm{F}_{(4,28)}=9.40, p<0.001\right.$ for METH; $\mathrm{F}_{(4,28)}=$ 4.47, $p<0.01$ for MRP, Figure 1c). These results indicate that glial cells may be involved in the development of the rewarding effects induced by METH and MRP in mice.

\section{Administration of ACM Enhances the Rewarding Effects of METH and MRP}

It is well known that the N.Acc. plays an important role in mediating the rewarding effects induced by many drugs of abuse (Wise and Hoffman, 1992; De Vries and Shippenberg, 2002). On the other hand, astrocyte could regulate the neuronal transmission by releasing neurotransmitters (Fellin and Carmignoto, 2004), neurotrophic factors (Brenneman et al, 1997: Bohn, 2004), cytokines, chemokines (Dong and Benveniste, 2001), and extracellular matrix (Brightman, 2002). To examine the role of astrocyte-related soluble factors in the development of the rewarding effects induced by drugs of abuse, ACM was injected into the N.Acc. (Figure 2a). In animals in which DMEM was injected into N.Acc., METH (0.0625, $0.125,0.25$, or $0.5 \mathrm{mg} / \mathrm{kg}$, s.c.), and MRP (1, 1.7, 3, or $5.6 \mathrm{mg} / \mathrm{kg}$, s.c.) each produced a dose-dependent preference for the drug-associated place (Figure $2 \mathrm{~b}$ and $\mathrm{c}$ ). Under these conditions, intra-N.Acc. administration of ACM clearly enhanced the rewarding effects of METH $\left(\mathrm{F}_{(9,58)}=6.14, p<0.001\right.$, Figure $\left.2 \mathrm{~b}\right)$ and $\operatorname{MRP}\left(\mathrm{F}_{(9,58)}=8.55, p<0.001\right.$, Figure $\left.2 \mathrm{c}\right)$ in mice.

\section{The Implication of Jak/STAT Pathway in the Enhancement by ACM of METH- and MRP-Induced Rewarding Effects}

Janus tyrosine kinase/signal transducers and activators of transcription (Jak/STAT) is a pathway that takes signals from the cell membrane to the nucleus in response to extracellular growth factors and cytokines (Justicia et al, 2000). In addition, the Jak/STAT pathway has been postulated to regulate astrogliosis and astrogliogenesis (Bonni et al, 1997; Sriram et al, 2004; He et al, 2005). The place preference produced by MRP ( $3 \mathrm{mg} / \mathrm{kg}$, s.c.), was significantly suppressed by intra-N.Acc. treatment with AG490 (0.1 nmol), which inhibits the Jak/STAT pathway $\left(\mathrm{F}_{(6,40)}=7.43, p<0.001\right.$, Figure $\left.3 \mathrm{~b}\right)$. Notably, the enhancement of the rewarding effect of METH $(0.5 \mathrm{mg} / \mathrm{kg}$, s.c.) by ACM was significantly blocked by intra-N.Acc. treatment with $\operatorname{AG} 490\left(\mathrm{~F}_{(6,41)}=8.025, p<0.001\right.$, Figure 3a). 
a In mouse cortical neuron/glia co-cultures
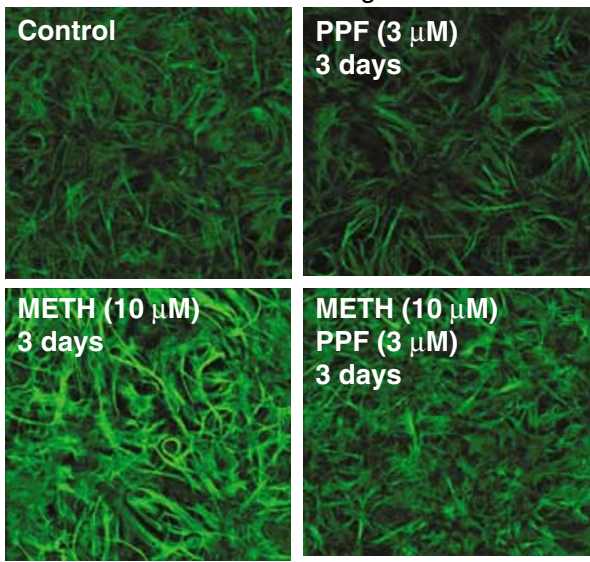

METH (10 $\mu \mathrm{M})$

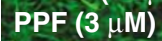

3 days
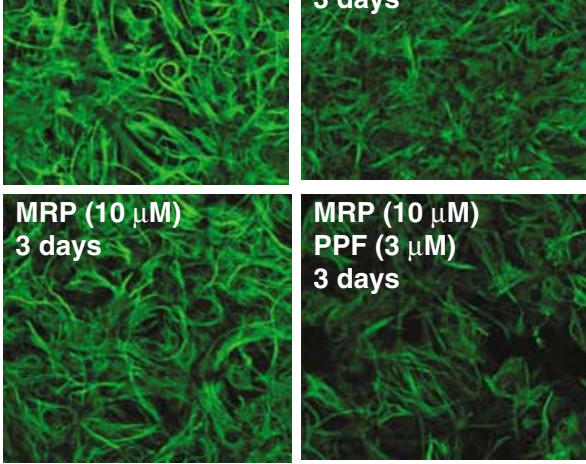

$\operatorname{MRP}(10 \mu \mathrm{M})$

PPF $(3 \mu \mathrm{M})$

3 days b Intensity of GFAP immunoreactivity

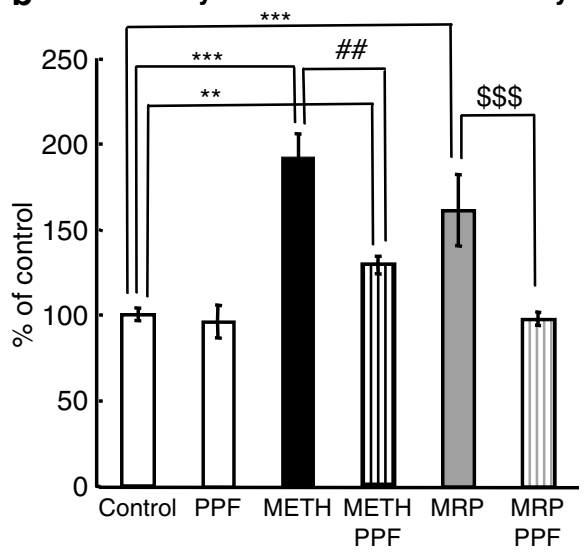

$\overline{50 \mathrm{~mm}}$

c

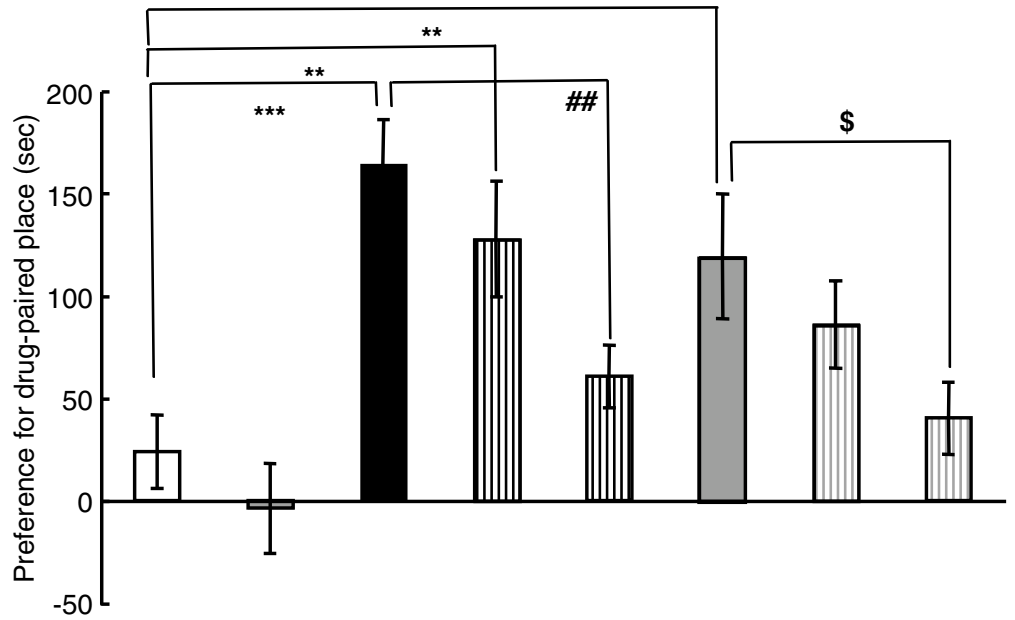

\begin{tabular}{|c|c|c|c|c|c|c|c|c|}
\hline $\begin{array}{c}\text { Pretreatment } \\
\text { (30 min before, i.p.) }\end{array}$ & Saline & PPF 3 & Saline & PPF 1 & PPF 3 & Saline & PPF 1 & PPF 3 \\
\hline $\begin{array}{l}\text { Conditioning } \\
\text { (mg/kg, s.c.) }\end{array}$ & & & & METH (1) & & & MRP (5) & \\
\hline
\end{tabular}

Figure I The effect of propentofylline (PPF) on the effects of methamphetamine (METH) and mophione (MRP). (a) Mouse cortical neuron/glia cocultures were treated with METH $(I 0 \mu \mathrm{M})$ or MRP $(10 \mu \mathrm{M})$ with or without PPF $(3 \mu \mathrm{M})$ for 3 days. The cells were stained with a polyclonal antibody to GFAP. (b) The intensity of GFAP-like immunoreactivity in each image was measured using NIH image. The level of GFAP-like immunoreactivity is expressed as a percent increase (mean \pm SEM) with respect to that in control cells. The statistical significance of differences between the groups was assessed with oneway ANOVA with Student's t-test. ${ }^{* *} p<0.0$ I, ${ }^{* * * *} p<0.00$ I vs control cells; ${ }^{\# \#} p<0.01$ vs METH-treated cells; ${ }^{\$ \$ \$} p<0.00$ I vs MRP-treated cells. (c) Chronic s.c. administration of either METH (I mg/ $/ \mathrm{kg})$ or MRP $(5 \mathrm{mg} / \mathrm{kg})$ produced a significant place preference in mice. Each column represents the mean \pm SEM of 8-10 mice. Mice were pretreated with PPF (I-3 mg/kg, i.p.) or saline 30 min before s.c. administration of saline, METH or MRP. The statistical significance of differences between the groups was assessed with one-way ANOVA followed by Bonferroni/Dunnett's test. $* *$ * $<<0.0$ I, **** $p<0.00$ I vs saline-saline group; ${ }_{\# \#} p<0.0$ I vs saline-METH group; ${ }^{\$} p<0.05$ vs saline-MRP group.

These results raise the possibility that astrocyte-released soluble factors could regulate the development of the rewarding effects induced by psychostimulants via Jak/ STAT pathway. Moreover, Jak/STAT-dependent astrogliosis and/or astrogliogenesis may play the important role in the development of the rewarding effects induced by psychostimulants.

\section{The Effects of ACM on the Differentiation of Multipotent NSCs Via Jak/STAT Pathway}

To ascertain whether ACM could induce Jak/STAT-dependent astrogliogenesis, we performed the differentiation experiments using multipotent NSCs obtained from the mouse forebrain. Interestingly, ACM clearly induced the 


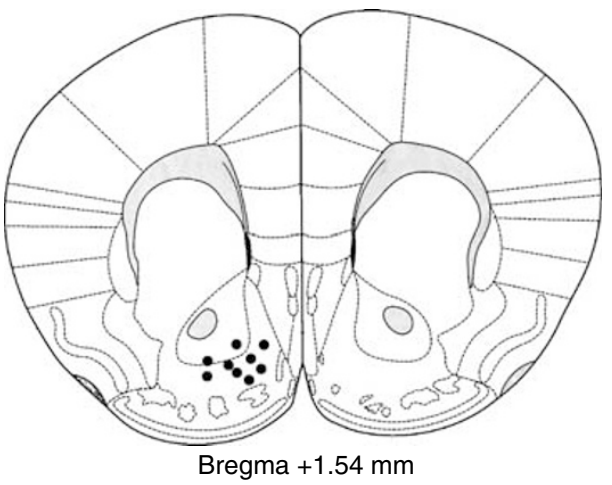

b

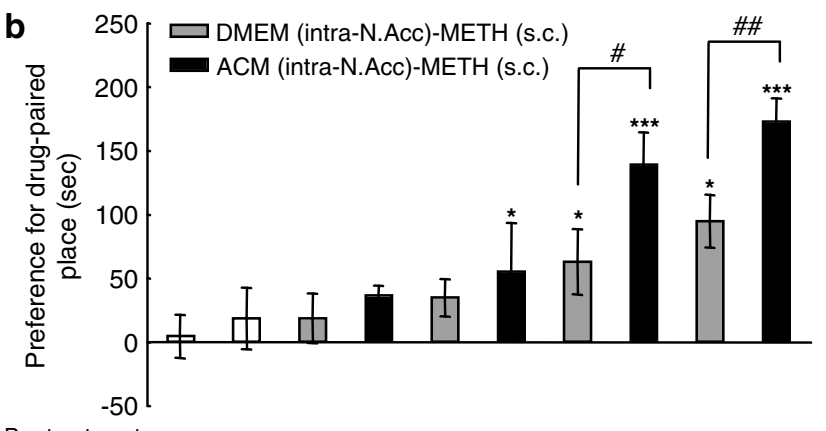

Pre-treatment DMEM ACM DMEM ACM DMEM ACM DDMEM ACM DMEM ACM \begin{tabular}{c|c|c|c|c|c} 
(intra-N.Acc.) & DMEM ACM & DMEM ACM & DMEM ACM & DMEM ACM & DMEM ACM \\
\hline $\begin{array}{c}\text { Conditioning } \\
\text { (mg/kg, s.c.) }\end{array}$ & Saline & METH & METH & METH & METH \\
$(0.0625)$ & $(0.125)$ & $(0.25)$ & $(0.5)$
\end{tabular}

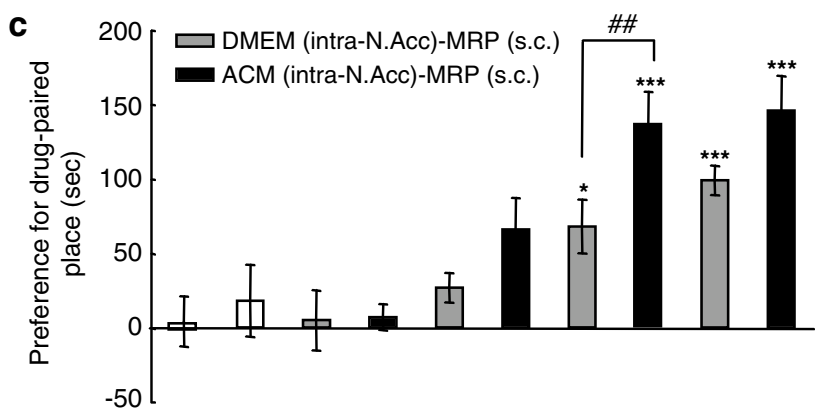

Pre-treatment |DMEM ACM DMEM ACM IDMEM ACM |DMEM ACM DMEM ACM \begin{tabular}{c|c|c|c|c|c} 
(intra-N.ACc.) & DMEM ACM & DMEM ACM & DMEM ACM & DMEM ACM & DMEM ACM \\
\hline Conditioning & Saline & MRP & MRP & MRP & MRP \\
$(1)$ & $(1.7)$ & $(3)$ & $(5.6)$
\end{tabular} (mg/kg, s.c.)

Figure 2 The effect of intra-nucleus accumbens (N.Acc.) administration of astrocyte-conditioned medium (ACM) on the place conditioning produced by METH and MRP in mice. (a) Dots represent microinjection regions in mice. The schematic brain sections are from the atlas (Paxinos and Franklin, 1997). (b) Mice were pretreated with DMEM or ACM into the N.Acc. I day before preconditioning test. In the conditioning session (3 days for METH, three days for saline), mice were treated with saline or METH $(0.0625,0.125,0.25$, or $0.5 \mathrm{mg} / \mathrm{kg}$, s.c.). Each point represents the mean \pm SEM of 7-8 mice. (c) Mice were pretreated with DMEM or ACM into the N.Acc. I day before preconditioning test. In the conditioning session ( 3 days for MRP, 3 days for saline), mice were treated with saline or $\operatorname{MRP}(\mathrm{I}, \mathrm{I} .7,3$, or $5.6 \mathrm{mg} / \mathrm{kg}$, s.c.). Each point represents the mean \pm SEM of 7-8 mice. The statistical significance of differences between the groups was assessed with one-way ANOVA followed by Bonferroni/Dunnett's test. * $p<0.05$, **** $p<0.001$ vs saline-conditioned group; ${ }^{\#} p<0.05,{ }^{\# \#} p<0.0$ I vs DMEM-pretreated group.

differentiation of multipotent NSCs into GFAP-positive astrocytes (Figure $4 \mathrm{a}$ and $\mathrm{c}$ ). This effect was reversed by cotreatment with AG490 (1 $\mu \mathrm{M}$, Figure $4 \mathrm{a}$ and $\mathrm{c})$. Conversely, treatment of NSCs with METH $(10 \mu \mathrm{M})$ failed to
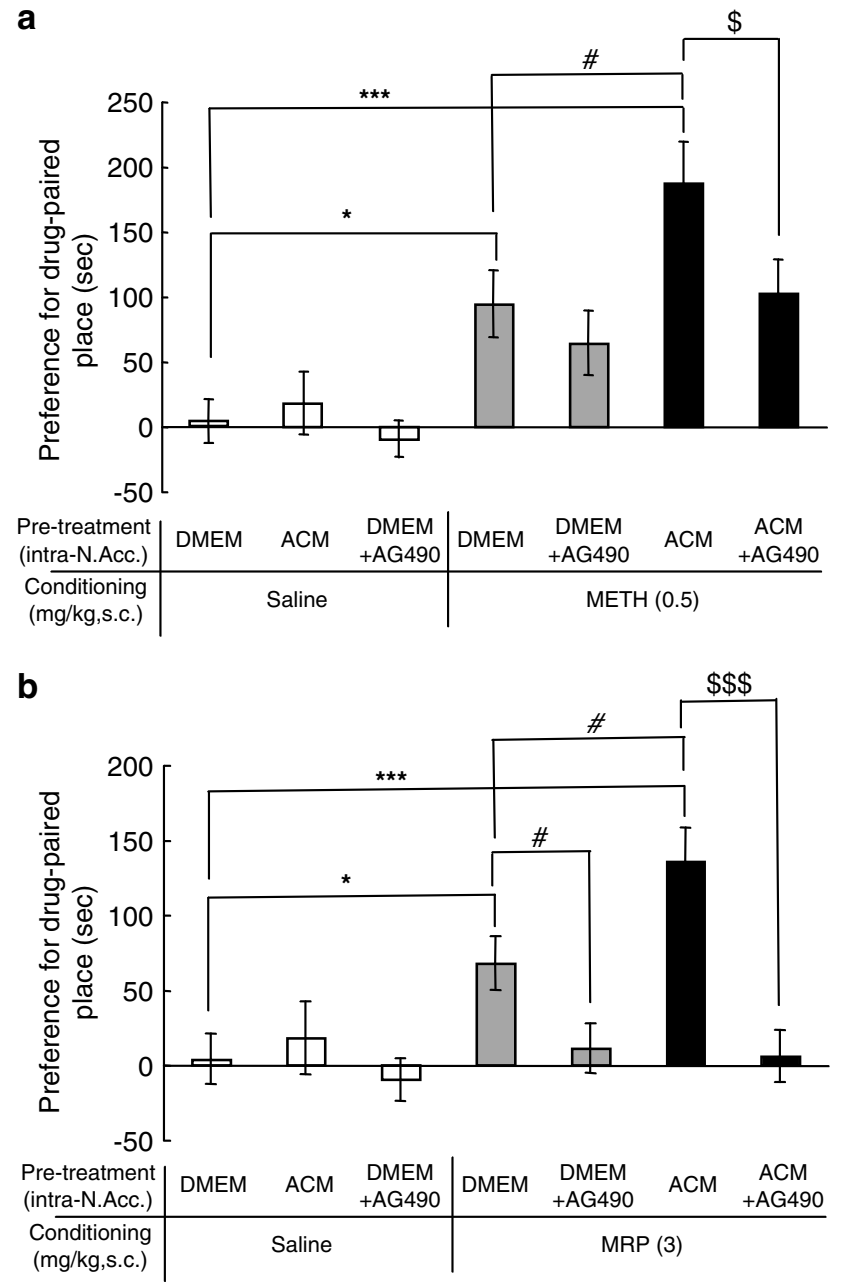

Figure 3 The effect of a Jak/STAT inhibitor AG490 on the enhancement by ACM of METH- and MRP-induced place preference in mice. (a) The enhancement by ACM of the METH $(0.5 \mathrm{mg} / \mathrm{kg}, \mathrm{s} . \mathrm{c}$.) $)$-induced place preference was significantly suppressed by the coinjection of AG490 $(0.1 \mathrm{nmol} / \mathrm{mouse})$ into the N.Acc. Each column represents the mean \pm SEM of 8-10 mice. ${ }^{*} p<0.05$, **** $p<0.00$ I vs DMEM-saline group; ${ }^{*} p<0.05$ vs DMEM-0.5 mg $/ \mathrm{kg}$ METH group; ${ }^{\$} p<0.05$ vs ACM- $0.5 \mathrm{mg} / \mathrm{kg}$ METH group. (b) The enhancement by ACM of the MRP ( $3 \mathrm{mg} / \mathrm{kg}$, s.c.)-induced place preference was significantly suppressed by the coinjection of AG490 $(0.1 \mathrm{nmol} /$ mouse $)$ into the N.Acc. Each column represents the mean \pm SEM of 7-8 mice. The statistical significance of differences between the groups was assessed with one-way ANOVA followed by Bonferroni/Dunnett's test. ${ }^{*} p<0.05$, **** $p<0.001$ vs DMEM-saline group; ${ }^{\#} p<0.05$ vs DMEM$3 \mathrm{mg} / \mathrm{kg}$ MRP group; ${ }^{\$ \$} p<0.001$ vs ACM-3 mg/kg MRP group.

induce the differentiation to GFAP-positive astrocytes (Figure $4 \mathrm{~b}$ and $\mathrm{d}$ ), indicating that ACM, but not METH itself, may induce astrogliogenesis via Jak/STAT pathway in the CNS.

\section{The Effect of METH-Treated ACM}

To examine whether ACM could promote astrogliosis, we next investigated the effect of ACM in the level of GFAP-like immunoreactivity in mouse purified cortical astrocytes. Treatment with DMEM or ACM for 1 day did not produce a significant increase in the level of GFAP-like immunoreactivity in mouse purified cortical astrocytes (Figure 5a 


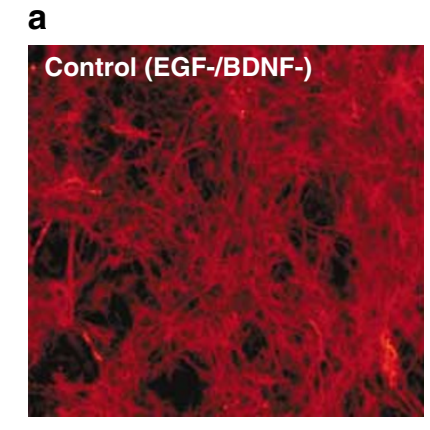
In multipotent neural stem cells
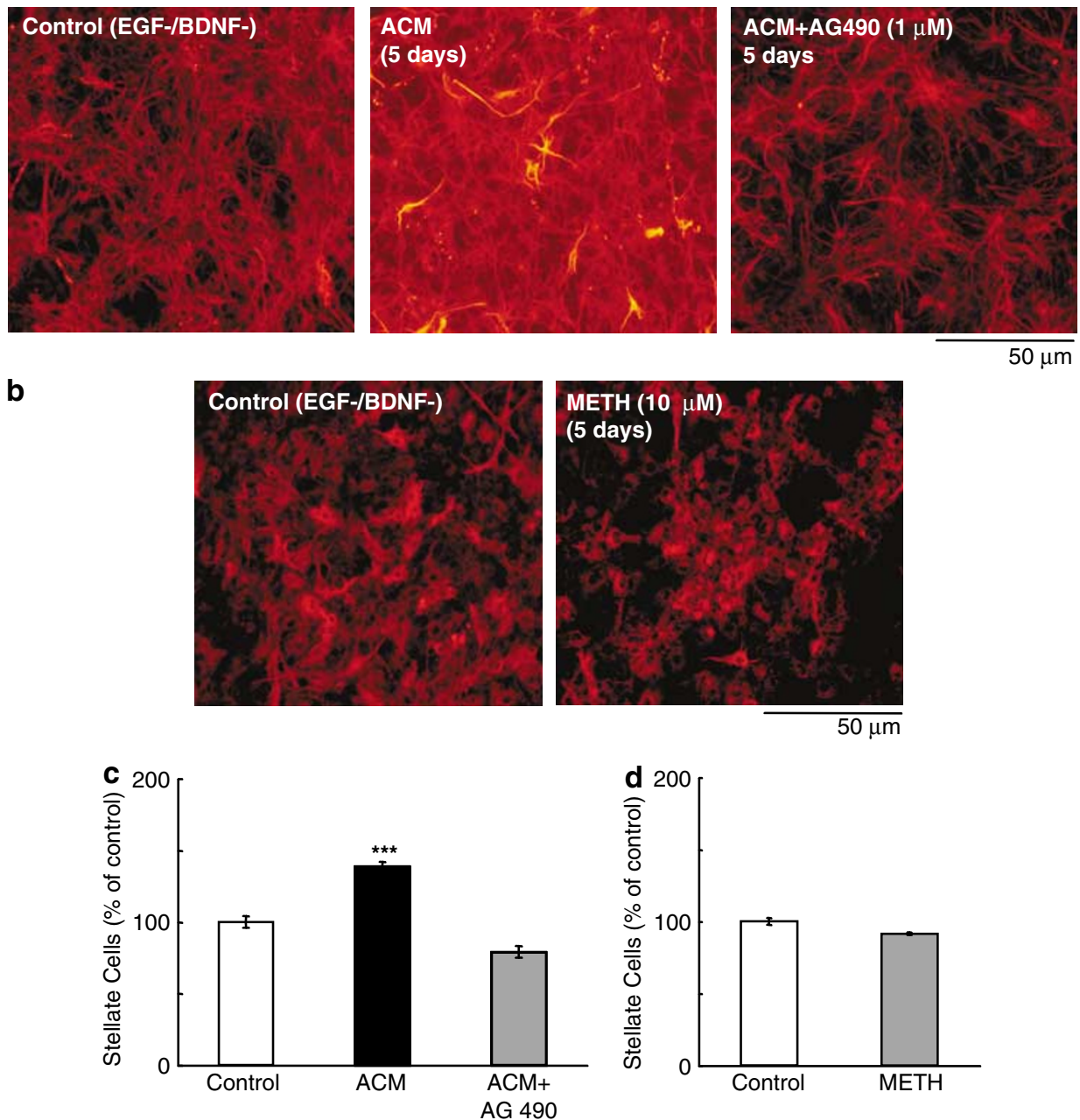

Figure 4 The effects of ACM on multipotent neural stem cells (NSCs). (a) NSCs were treated with ACM with or without AG490 (I $\mu$ M) for 5 days. The cells were stained with a polyclonal antibody to GFAP. (b) NSCs were treated with METH $(I 0 \mu M)$ for 5 days. The cells were stained with a polyclonal antibody to GFAP. (c and d) The differentiation of NSCs into GFAP-positive stellate astrocytes was evaluated. Data represent the mean (\% of control) \pm SEM. The statistical significance of differences between the groups was assessed with one-way ANOVA with Student's t-test. ***** $<0.00$ I vs control cells.

and b). Treatment with ACM collected from METH (10 or $100 \mu \mathrm{M}, 3$ days)-treated astrocytes (METH 10-ACM and METH 100-ACM) for 1 day induced a robust activation of astrocyte, as detected by an increase in the level of GFAPlike immunoreactivity, in mouse purified cortical astrocytes $\left({ }^{* *} p<0.01,{ }^{* *} p<0.001 v s\right.$ DMEM-treated cells, Figure 5a and $b)$. On the other hand, treatment with ACM collected from MRP (10 or $100 \mu \mathrm{M}, 3$ days)-treated astrocytes did not produce any morphological changes in mouse purified cortical astrocytes (Figure $5 \mathrm{a}$ and $\mathrm{b}$ ). These results suggest that METH-, but not MRP-, treated astrocytes could release some soluble factors which could enhance the activation of astrocytes.

We previously reported that in vitro treatment with $100 \mu \mathrm{M}$ of METH caused neuronal cell death (Narita et al, 2005a). On the other hand, in vitro treatment with $10 \mu \mathrm{M}$ of METH could cause the activation of astrocytes without neuronal cell death (Narita et al, 2005a). Therefore, $100 \mu \mathrm{M}$ of METH might have some neurotoxic effects in cultured cells. In the present study, intra-N.Acc. administration of METH 10-ACM dramatically enhanced the rewarding effects of $\operatorname{METH}\left(\mathrm{F}_{(5,35)}=10.25, p<0.001\right.$, Figure 5c), indicating that astrocyte-related soluble factors released from METHtreated astrocytes potentiate the expression of the rewarding effect induced by METH.

\section{ACM Contains Some Chemokines}

As mentioned above, Jak/STAT pathway could modulate the development of the rewarding effects induced by METH and MRP. The Jak/STAT pathway is coupled to many key cytokine/chemokine receptors and is thus a primary conduit for cytokine/chemokine signal transduction and cellular communication (Campbell, 2005). Therefore, we hypothesized that astrocyte-related cytokines and/or chemokines may contribute to the development of the rewarding effects induced by METH and MRP. Based on this hypothesis, we next performed the cytokine assay. We found that some chemokines, such as monocyte chemoattractant protein-5 (MCP-5) and soluble tumor necrosis factor receptor 1 (sTNFR1), were identified in both ACM and METH10-ACM (Figure 6). 
In mouse purified cortical astrocytes
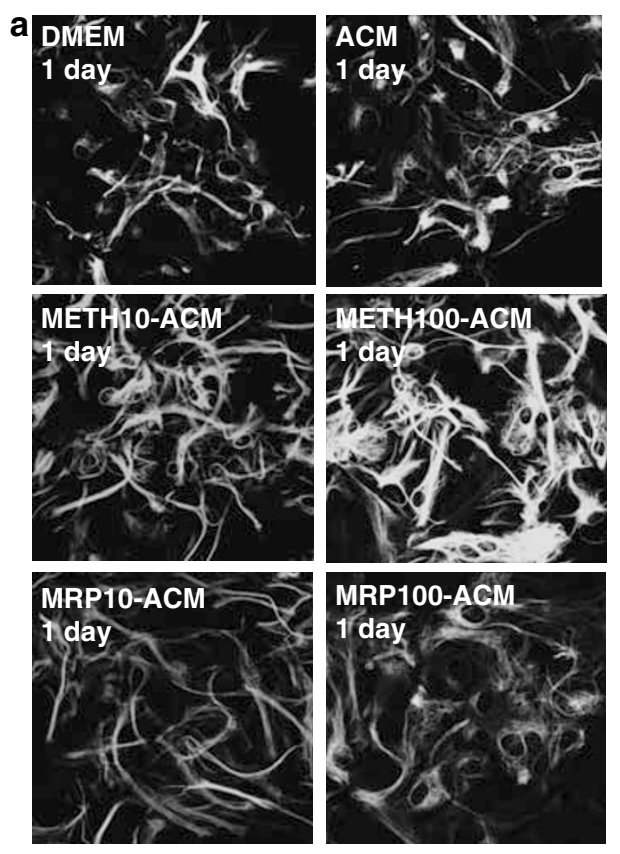

$50 \mu \mathrm{m}$

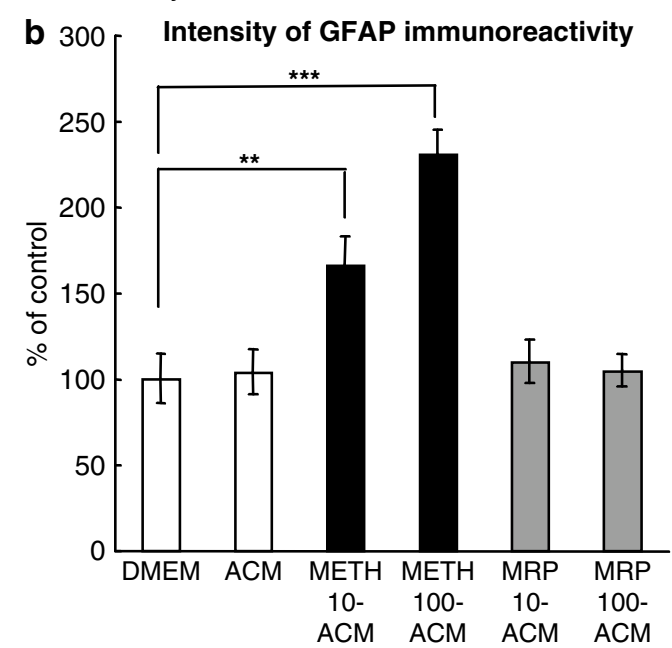

C

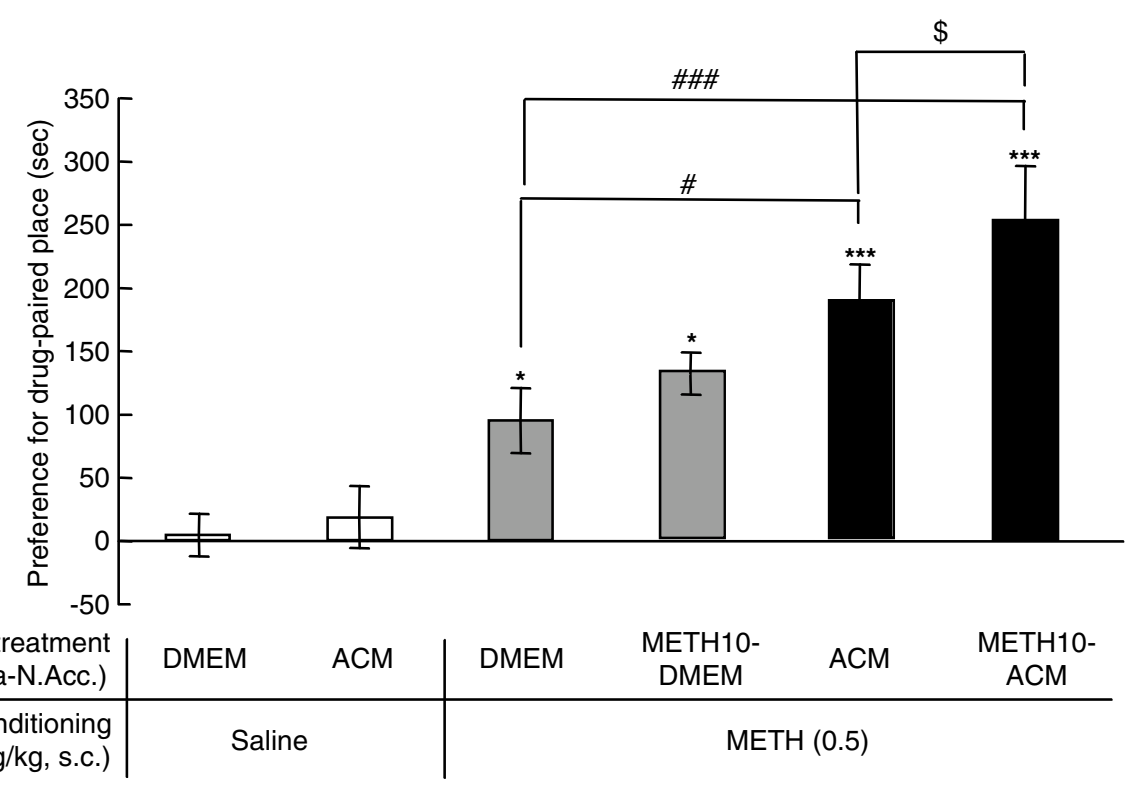

Figure 5 The effect of intra-N.Acc. administration of METH ( $10 \mu \mathrm{M}, 3$ days)-treated conditioned medium (METHIO-ACM) on the place conditioning produced by METH in mice. (a) Mouse-purified cortical astrocytes ware treated with DMEM, ACM, METH (10 and $100 \mu \mathrm{M}, 3$ days)-treated astrocyteconditioned medium (METH I0-ACM or METH I00-ACM), or MRP (I0 and I00 $\mu$ M, 3 days)-treated astrocyte-conditioned medium (MRP I0-ACM or MRP I00-ACM). The cells were stained with a polyclonal antibody to GFAP. (b) The intensity of GFAP-like immunoreactivity in each image was measured using $\mathrm{NIH}$ image. The level of GFAP-like immunoreactivity is expressed as a percent increase (mean $\pm \mathrm{SEM}$ ) with respect to that in control cells. The statistical significance of differences between the groups was assessed with one-way ANOVA with Student's t-test. *** $<<0.01$, **** $p<0.00$ I vs control cells. (c) Intra-N.Acc. administration of METH I0-ACM significantly potentiated the rewarding effect of METH (0.5 mg/kg, s.c.) in mice. Each column represents the mean \pm SEM of 7-8 mice. The statistical significance of differences between the groups was assessed with one-way ANOVA followed by Bonferroni/

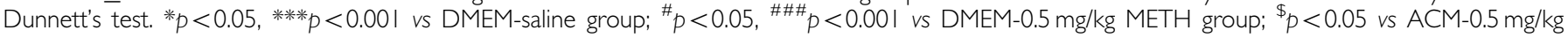
METH group.

The Effect of Intra-N.Acc. Administration of MCM on the Rewarding Effect Induced by METH and MRP

Microglial cells are the major immunocompetent cells in the brain and include signaling cascades involving cytokines and chemokines (Färber and Kettenmann,
2005). As mentioned above, Jak/STAT pathway and/or chemokines regulate the enhancement of the rewarding effect of METH and MRP by ACM. Therefore, we next investigated the effect of microgia-related soluble factors on the development of the rewarding effects induced by METH and MRP. 

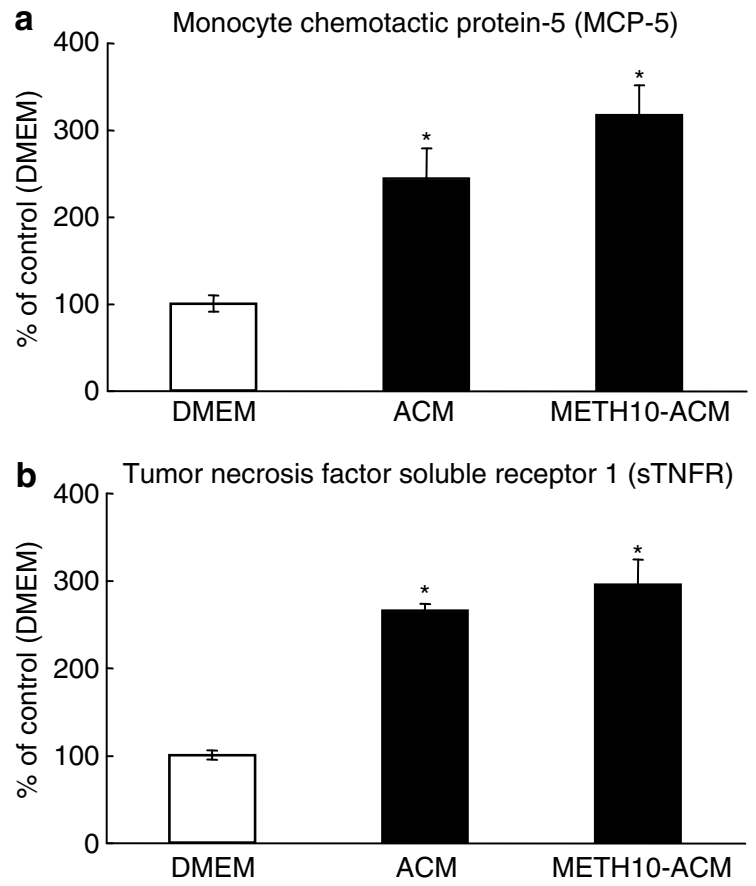

Figure 6 Cytokine array of DMEM, ACM, and METHIO-ACM. DMEM (control), ACM, or METHIO-ACM was incubated with cytokine array membranes using anticytokine antibodies. The changes in the immunoreactivity of monocyte chemotactic protein-5 (MCP-5, a) and tumor necrosis factor soluble receptor-I (sTNFR, b) are expressed as a percent increase (mean \pm SEM) with respect to that in control (DMEM) cells. The statistical significance of differences between the groups was assessed with one-way ANOVA with Student's t-test. ${ }^{*} p<0.05$ vs control.

Treatment with METH $(10-100 \mu \mathrm{M})$ for 3 days in mouse purified cortical microglia caused a swelling morphology and an increase in the level of immunoreactivity of OX-42, which is a marker of microglia (Figure 7a). On the other hand, treatment with MRP (1-100 $\mu \mathrm{M}, 3$ days) failed to induce any morphological changes in mouse purified cortical microglia (Figure 7a).

In contrast to ACM, however, intra-N.Acc. administration of MCM failed to enhance the rewarding effects induced by METH (Figure 7b) and MRP Figure 7c) in mice.

\section{The Effect of Intra-CG Administration of ACM on the Rewarding Effect Induced by METH and MRP}

The CG is responsible for stimulus-reward learning (Allman et al, 2001). To compare the effect of intra-N.Acc. administration of ACM, we next investigated the effect of intra-CG administration of ACM on the rewarding effect of METH and MRP. In animals in which DMEM was injected into the CG, METH $(0.0625,0.125,0.25$, or $0.5 \mathrm{mg} / \mathrm{kg}$, s.c.), and MRP $(1,1.7,3$, or $5.6 \mathrm{mg} / \mathrm{kg}$, s.c.) produced a dosedependent preference for the drug-associated place (Figure $8 \mathrm{~b}$ and $\mathrm{c}$ ). Under these conditions, intra-CG administration of ACM clearly enhanced the rewarding effect of METH $\left(\mathrm{F}_{(9,57)}=8.80, p<0.001\right.$, Figure $\left.8 \mathrm{~b}\right)$ and $\operatorname{MRP}\left(\mathrm{F}_{(9,58)}=\right.$ $16.71, p<0.001$, Figure $8 \mathrm{c}$ ) in mice.
The Effect of Intra-CPu Administration of ACM on the Rewarding Effect Induced by METH and MRP

The $\mathrm{CPu}$ is regulated by dopaminergic inputs from the substantia nigra. Intra-CPu administration of ACM failed to enhance the rewarding effects induced by METH (Figure $9 \mathrm{~b}$ ) and MRP (Figure 9c) in mice.

\section{DISCUSSION}

Astrocytes are the most numerous cells in the mammalian CNS, with well-established roles in providing structural, metabolic, and trophic support to neurons. Astrocytes also can be recruited for neurotransmission and exert a modulatory action on synaptic functions. In the present study, we further investigated the direct action of astrocytes on the development of the rewarding effects induced by drugs of abuse. We found here that astrocyte-, but not microglia-, related soluble factors may directly modulate the development of the rewarding effects induced by METH and MRP.

PPF is a xanthine derivative with pharmacological effects different from those of the classical methylxanthines, caffeine, and theophylline. PPF is known to modulate glial activity under pathological condition (Raghavendra et al, 2004). The mechanism of glial modulation by PPF under pathological condition could be due to its inhibitory action of phosphodiesterase enzymes and subsequent augmentation of cAMP signaling (Schubert et al, 1997). It has been reported that the activity of cAMP could regulate the morphology of astrocytes (Won and Oh, 2000). In the present study, we found that the METH- or MRPinduced activation of astrocytes was dramatically diminished by treatment with PPF. Thus, PPF may inhibit the activity of phosphodiesterase in glial cells, resulting in the inhibition of the activation of astrocytes induced by drugs of abuse. We also demonstrated that the place preference produced by repeated in vivo treatment of either METH or MRP was significantly suppressed by i.p. treatment with the glial modulator PPF. These findings provide evidence that the modulation of glial activity may contribute to the development of the rewarding effects induced by METH and MRP.

We next investigated whether astrocyte-related soluble factors could regulate the development of psychological modulation on METH and MRP. In the present study, intraN.Acc. administration of ACM dramatically enhanced the rewarding effects of METH and MRP. These data suggest that astrocyte-related soluble factors induced by drugs of abuse may directly regulate the development of their rewarding effects.

Chronic administration of cocaine induces the upregulation of Jak/STAT pathway in the VTA (Berhow et al, 1996). It has been reported that treatment with METH at neurotoxic doses induces the robust phosphorylation of STAT3 in the mouse brain (Hebert and O'Callaghan, 2000). These findings raise the possibility that exposure to the drugs of abuse could produce the synaptic plasticity and/or neuronal toxicity via Jak/STAT pathway. In the present study, the enhancement of METH-induced rewarding effects by ACM was blocked by intra-N.Acc. administration of the Jak/STAT inhibitor AG490, suggesting that astrocyte-related 
a
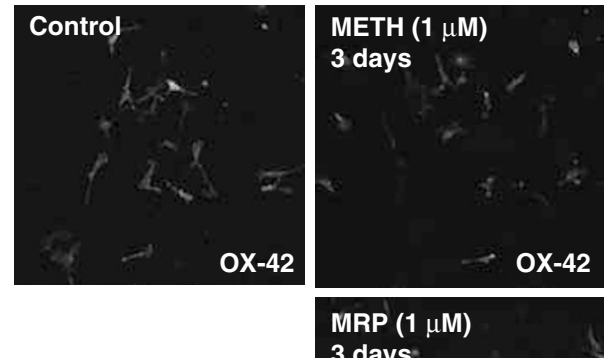

3 days

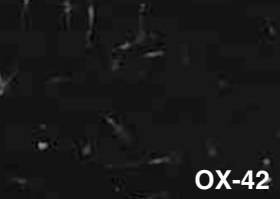

$0 \times-42$

b

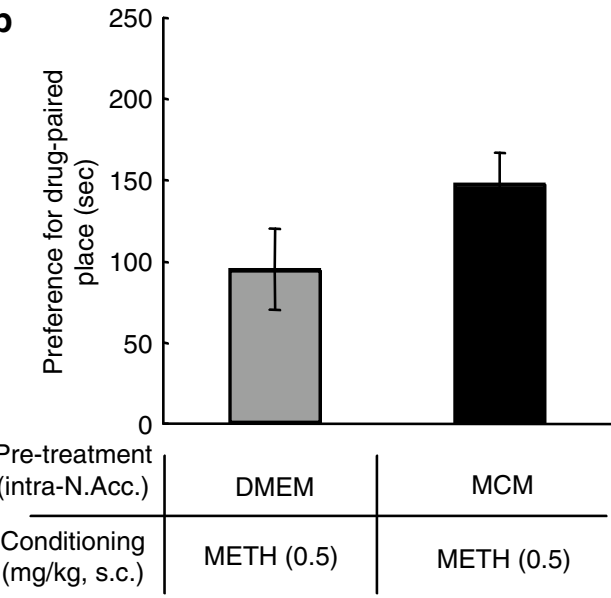

cortical microglia

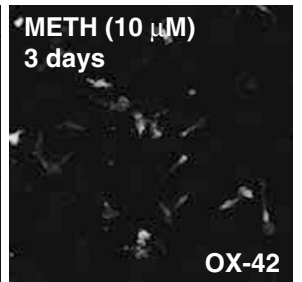

MRP $(10 \mu \mathrm{M})$ 3 days

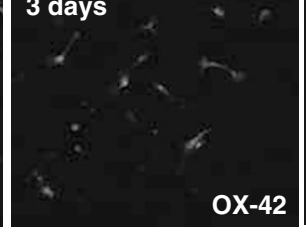

$0 X-42$

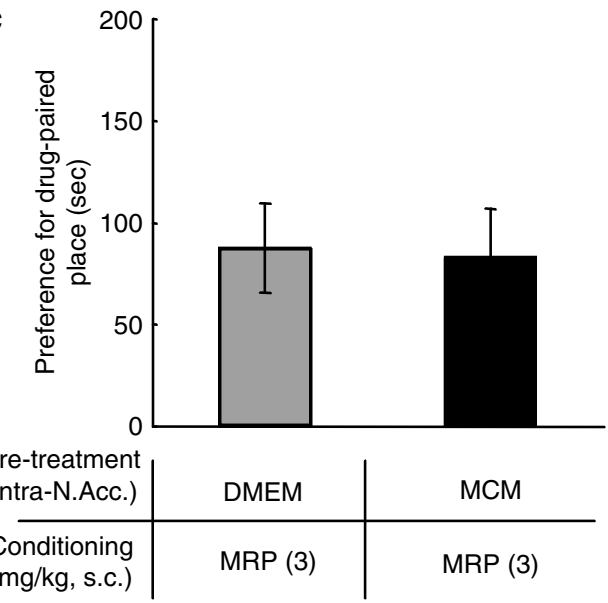

Figure 7 The effects of intra-N.Acc. administration of microglia-conditioned medium (MCM) on the place conditioning produced by METH and MRP in mice. (a) Purified cortical microglia were incubated with normal medium, METH (I-100 $\mu \mathrm{M})$ or MRP $(1-100 \mu \mathrm{M})$ for 3 days. The cells were stained with a rat antibody to OX-42. (b, c) Intra-N.Acc. administration of MCM failed to induce a significant enhancement in either METH (0.5 mg/kg, s.c., b)- or MRP $(3 \mathrm{mg} / \mathrm{kg}, \mathrm{s} . \mathrm{c} ., \mathrm{c})$-induced rewarding effect in mice. Each column represents the mean \pm SEM of 7-8 mice. The statistical significance of differences between the groups was assessed with one-way ANOVA with Student's t-test. There were no statistical significances of difference between two groups.

soluble factors enhance the development of METH-induced rewarding effects via the Jak/STAT pathway.

$\mu$-Opioid receptors, which have been reported to play a role in several of MRP's pharmacological effects, are the member of the G-protein-coupled-receptor superfamily (Narita et al, 2001). Agonist stimulation of many Gprotein-coupled receptors has been shown to result in tyrosine phosphorylation and activation of Jak and STAT family members, leading to changes in gene transcription (Campbell, 2005). It has been reported that STAT3 signaling regulates the neuronal growth and differentiation by $\mu$ opioid receptor stimulation in neuroblastoma SH-SY5Y cells (Yuen et al, 2004). MRP exposed to COS-7 cells, which are transfected with $\mu$-opioid receptors and STAT5A, induces receptor-dependent tyrosine phosphorylation of STAT5A (Mazarakou and Georgoussi, 2005). In the present study, we demonstrated that both the expression of and ACM-induced enhancement of MRP-induced rewarding effects were blocked by intra-N.Acc. administration of AG490. Thus, it seems likely that chronic treatment with MRP may activate the Jak/STAT pathway via $\mu$-opioid receptors, resulting in the development and expression of rewarding effects in mice.

The Jak/STAT pathway modulates astrogliosis and/or astrogliogenesis (Bonni et al, 1997; Sriram et al, 2004; He et $a l, 2005)$. It should be mentioned that ACM, but not METH itself, induced the differentiation of NSCs into GFAP-positive astrocytes via the Jak/STAT pathway. On the other hand, the treatment with METH-ACM, but not ACM or MRP-ACM, induced the activation of astrocytes in mouse-purified cortical astrocytes. Furthermore, intraN.Acc. administration of METH-ACM significantly and dramatically enhanced the rewarding effect of METH. These findings suggest that astrocyte-related soluble factors could cause astrogliogenesis via the Jak/STAT pathway, promoting the development and expression of rewarding effect induced by METH. Moreover, METH-induced astrocytic secretion might enhance the intensity of astrocytic activation in the CNS. Although the exact binding site for METH in astrocytes or the mechanism underlying METH-induced astrocytic secretion is unclear at this time, METH, which could be taken up by astrocytes across the astrocytic plasma 
a
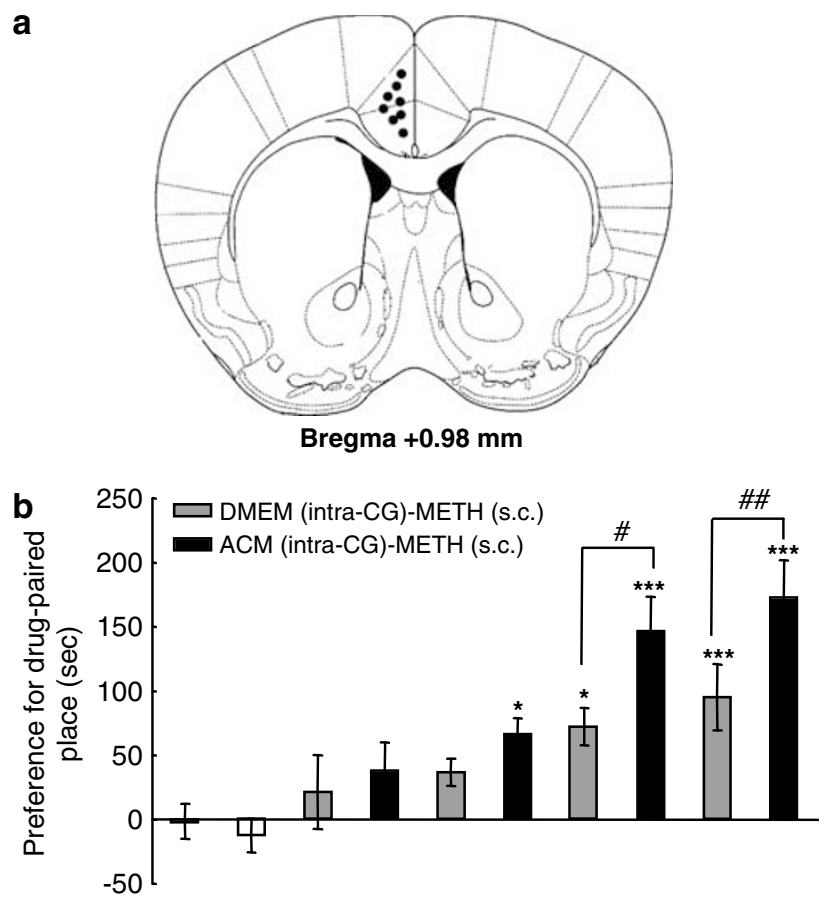

Pre-treatment
(intra-CG)

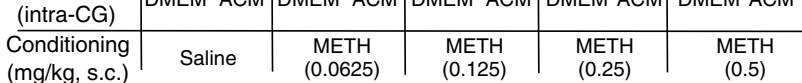

c

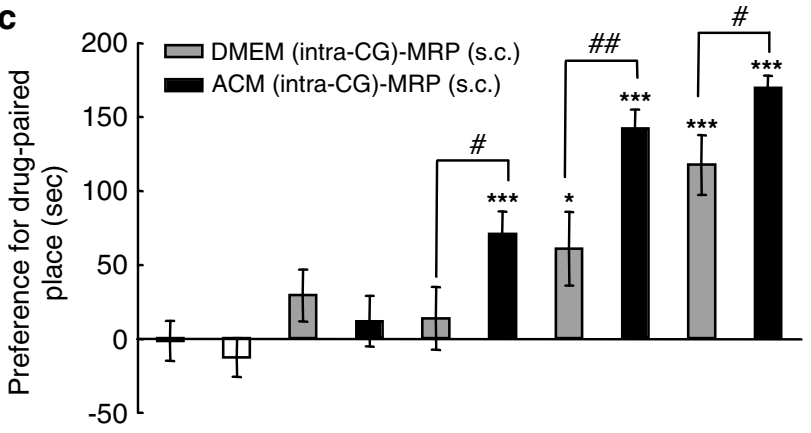

Pre-treatment DMEM ACM JDMEM ACM DMEM ACM DMEM ACM DMEM ACM

\begin{tabular}{c|c|c|c|c|c} 
(intra-CG) & DMEM ACM & DMEM ACM & DMEM ACM & DMEM ACM & DMEM ACM \\
\hline $\begin{array}{c}\text { Conditioning } \\
\text { (mg } / \mathrm{kg}, \text { s.c.) }\end{array}$ & Saline & MRP & MRP & MRP & MRP \\
& & $(1)$ & $(1.7)$ & (3) & (5.6)
\end{tabular}

Figure 8 The effect of intra-cingulate cortex (CG) administration of astrocyte-conditioned medium (ACM) on the place conditioning produced by METH and MRP in mice. (a) Dots represent microinjection regions in mice. The schematic brain sections are from the atlas (Paxinos and Franklin, 1997). (b) Mice were pretreated with DMEM or ACM into the CG I day before preconditioning test. In the conditioning session ( 3 days for METH, 3 days for saline), mice were treated with saline or METH $(0.0625,0.125$, 0.25 , or $0.5 \mathrm{mg} / \mathrm{kg}$, s.c.). Each point represents the mean \pm SEM of $7-8$ mice. (c) Mice were pretreated with DMEM or ACM into the CG I day before preconditioning test. In the conditioning session ( 3 days for MRP, 3 days for saline), mice were treated with saline or $\operatorname{MRP}(\mathrm{I}, 1.7,3$, or $5.6 \mathrm{mg} / \mathrm{kg}$, s.c.). Each point represents the mean \pm SEM of 7-8 mice. The statistical significance of differences between the groups was assessed with one-way ANOVA followed by Bonferroni/Dunnett's test. * $p<0.05$, **** $p<0.00$ I vs saline-conditioned group; ${ }^{\#} p<0.05,{ }^{\# \#} p<0.01$ vs DMEM-pretreated group.

membranes, cause astrocytic secretion, and potentiate the development of the rewarding effect induced by METH.

Recently, we reported that METH and MRP differentially regulated long-term changes in neuron-astrocytes commu-
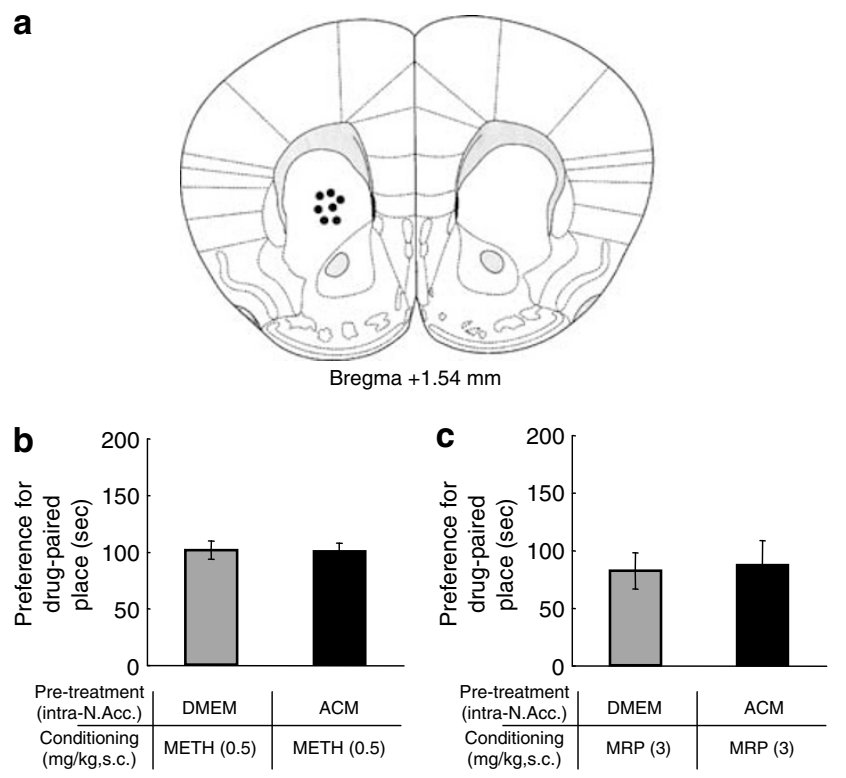

Figure 9 The effect of intra-corpus striatum (CPu) administration of astrocyte-conditioned medium (ACM) on the place conditioning produced by METH and MRP in mice. (a) Dots represents microinjection regions in mice. The schematic brain sections are from the atlas (Paxinos and Franklin, 1997). (b) Intra-CPu administration of ACM failed to induce a significant enhancement in either METH (0.5 mg/ $/ \mathrm{kg}$, s.c., b)- or MRP (3 mg/ $/ \mathrm{kg}$, s.c., c)induced rewarding effect in mice. Each column represents the mean \pm SEM of 7-8 mice. The statistical significance of differences between the groups was assessed with one-way ANOVA with Student's $t$-test. There were no statistical significances of difference between two groups.

nication in the CNS. In this study, we demonstrated that cortical purified astrocytes were markedly activated by METH. Opioid receptors are widely expressed by astrocytes, and the activation of $\mu$-opioid receptors can modulate programmed cell death (Stiene-Martin et al, 1998; Khurdayan et al, 2004). Unlike METH, however, MRP failed to induce the morphological change in cortical purified astrocytes (Narita et al, 2005a). Furthermore, METH, but not MRP, caused a long-lasting astrocytic activation in cortical neuron/glia cocultures (Narita et al, 2005a). In the present study, we also observed the difference between METH-treated ACM (METH-ACM) and MRP-treated ACM (MRP-ACM), while METH-ACM markedly activated astrocytes with morphological changes in astrocytes, MRP-ACM had no such effect. The data suggest that METH, but not MRP may directly affect astrocytes and lead to the release of astrocyte-related soluble factors, resulting in the robust enhancement of the development of the rewarding effect induced by METH.

The Jak/STAT pathway transduces signals from cytokines and chemokines. In the present study, some chemokiens, such as MCP-5 and sTNFR1, were identified in ACM and METH-ACM. MCP-5 is a mouse homologue to MPC-1 (El-Hage et al, 2005). In addition, treatment with MRP induces the secretion of MCP-1 from astrocytes (El-Hage et al, 2005). On the other hand, the biological functions of the sTNFR1 are not completely understood. However, TNF- $\alpha$ and other cytokines can bind to this receptor (Ryan and Nicklas, 2004). Some kinds of drugs of abuse, such as MRP (Kapasi et al, 2000) and METH (Lee et al, 2001), could induce the generation of TNF- $\alpha$, which may in turn 
stimulate the release of sTNFR1 as astrocyte-related soluble factors. Collectively, these astrocyte-related chemokines may, at least in part, contribute to the positive regulation of neuron-glia communication during the development of the rewarding effects induced by drugs of abuse.

Cytokines, chemokines, and their receptors play a major role in the immune responses of the CNS. They are expressed at constitutively low levels in microglia, and induced by inflammatory mediators (Mennicken et al, 1999; Färber and Kettenmann, 2005). Moreover, microglial cells are known to response to drugs of abuse, such as MRP and METH (Guilarte et al, 2003; Thomas et al, 2004; Khurdayan et al, 2004). In the present study, treatment with METH caused a morphological change in purified microglia, whereas MRP had no such effect. In contrast to ACM, intra-N.Acc. administration of MCM failed to enhance the rewarding effects induced by METH and MRP. Thus, it seems likely that METH-induced morphological changes in cortical microglia are not essential for the development of METH-induced rewarding effect. Collectively, these findings indicate that astrocyte-, but not microglia-, related soluble factors could potentially regulate the development of the rewarding effects induced by drugs of abuse.

It is of interest to note that intra-CG administration of ACM also significantly enhanced the rewarding effects of METH and MRP. The CG projects to the mediodorsal caudate, lateral part of the mediodorsal nucleus of the thalamus, and amygdala (Bussey et al, 1996). In addition, CG receives major dopaminergic input from the VTA (Retaux et al, 1994). The CG is, therefore, linked to emotional states and responsible for stimulus-reward learning (Allman et al, 2001). Moreover, we previously reported that the level of GFAP in the mouse CG was clearly increased by chronic in vivo administration of $\mathrm{METH}$ (Narita et al, 2005a). Taken together, these results indicate that astrocyte-released soluble factors directly modify the neuron/glia communication in the CG during the development of the rewarding effects induced by METH and MRP.

Unlike intra-N.Acc. and intra-CG administration of ACM, intra- $\mathrm{CPu}$ administration of ACM failed to enhance the rewarding effects induced by METH and MRP. These data suggest that astrocyte-related soluble factors could regulate the development of the rewarding effect induced by drugs of abuse in specific brain regions, such as the N.Acc. and CG.

In conclusion, we demonstrated here that the activation of astrocytes in the N.Acc. and/or CG provides a powerful signal for dopamine-associated behaviors, habits and addiction by drugs of abuse at the synaptic levels. Our findings suggest that astrocyte-, but not microglia-, related soluble factors could directly amplify the development of rewarding effect induced by METH and MRP in the N.Acc. and CG. The present findings provide a new insight into the basis of synaptic plasticity during the development of the rewarding effects induced by drugs of abuse.

\section{ACKNOWLEDGEMENTS}

This work was supported in part by grants from the Ministry of Heath, Labor and Welfare, and the Ministry of Education, Culture, Sports, Science and Technology of Japan.

\section{REFERENCES}

Abrous DN, Koehl M, Le Moal M (2005). Adult neurogenesis: from precursors to network and physiology. Physiol Rev 85: 523-569.

Allman JM, Hakeem A, Erwin JM, Nimchinsky E, Hof P (2001). The anterior cingulate cortex. The evolution of an interface between emotion and cognition. Ann NY Acad Sci 935: 107-117.

Berhow MT, Hiroi N, Kobierski LA, Hyman SE, Nestler EJ (1996). Influence of cocaine on the JAK-STAT pathway in the mesolimbic dopamine system. J Neurosci 16: 8019-8026.

Brenneman DE, Phillips TM, Festoff BW, Gozes I (1997). Identity of neurotrophic molecules released from astroglia by vasoactive intestinal peptide. Ann NY Acad Sci 814: 167-173.

Brightman MW (2002). The brain's interstitial clefts and their glial walls. J Neurocytol 31: 595-603.

Bohn MC (2004). Motoneurons crave glial cell line-derived neurotrophic factor. Exp Neurol 190: 263-275.

Bonni A, Sun Y, Nadal-Vicens M, Bhatt A, Frank DA, Rozovsky I et al (1997). Regulation of gliogenesis in the central nervous system by the JAK-STAT signaling pathway. Science 278: 477483.

Bowers MS, Kalivas PW (2003). Forebrain astroglial plasticity is induced following withdrawal from repeated cocaine administration. Eur J Neurosci 17: 1273-1278.

Bussey TJ, Muir JL, Everitt BJ, Robbins TW (1996). Dissociable effects of anterior and posterior cingulate cortex lesions on the acquisition of a conditional visual discrimination: facilitation of early learning $v s$ impairment of late learning. Behav Brain Res 82: $45-56$.

Campbell IL (2005). Cytokine-mediated inflammation, tumorigenesis, and disease-associated JAK/STAT/SOCS signaling circuits in the CNS. Brain Res Rev 48: 166-177.

De Vries TJ, Shippenberg TS (2002). Neural systems underlying opiate addiction. J Neurosci 22: 3321-3325.

Dong Y, Benveniste EN (2001). Immune function of astrocytes. Glia 36: 180-190.

El-Hage N, Gurwell JA, Singh IN, Knapp PE, Nath A, Hauser KF (2005). Synergistic increases in intracellular $\mathrm{Ca}^{2+}$, and the release of MCP-1, RANTES, and IL- 6 by astrocytes treated with opiates and HIV-1 Tat. Glia 50: 91-106.

Färber K, Kettenmann H (2005). Physiology of microglial cells. Brain Res Rev 48: 133-143.

Flores C, Samaha AN, Stewart J (2000). Requirement of endogenous basic fibroblast growth factor for sensitization to amphetamine. J Neurosci 20: RC55.

Fellin T, Carmignoto G (2004). Neurone-to-astrocyte signalling in the brain represents a distinct multifunctional unit. J Physiol 559: 3-15.

Guilarte TR, Nihei MK, McGlothan JL, Howard AS (2003). Methamphetamine-induced deficits of brain monoaminergic neuronal markers: distal axotomy or neuronal plasticity. Neuroscience 122: 499-513.

He F, Ge W, Martinowich K, Becker-Catania S, Coskun V, Zhu W et al (2005). A positive autoregulatory loop of Jak-STAT signaling controls the onset of astrogliogenesis. Nat Neurosci 8: 616-625.

Hebert MA, O'Callaghan JP (2000). Protein phosphorylation cascades associated with methamphetamine-induced glial activation. Ann NY Acad Sci 914: 238-262.

Hyman SE, Malenka RC (2001). Addiction and the brain: the neurobiology of compulsion and its persistence. Nat Rev Neurosci 2: 695-703.

Justicia C, Gabriel C, Planas AM (2000). Activation of the JAK/STAT pathway following transient focal cerebral ischemia: signaling through Jak1 and STAT3 in astrocytes. Glia 30: 253-270.

Kapasi AA, Gibbons N, Mattana J, Singhal PC (2000). Morphine stimulates mesangial cell TNF- $\alpha$ and nitrite production. Inflammation 24: 463-476. 
Khurdayan VK, Buch S, El-Hage N, Lutz SE, Goebel SM, Singh IN et al (2004). Preferential vulnerability of astroglia and glial precursors to combined opioid and HIV-1 Tat exposure in vitro. Eur J Neurosci 19: 3171-3182.

Kimelberg HK, Narumi S, Bourke RS (1978). Enzymatic and morphological properties of primary rat brain astrocyte cultures, and enzyme development in vivo. Brain Res 153: 55-77.

Lee YW, Hennig B, Yao J, Toborek M (2001). Methamphetamine induces AP-1 and NF-kappaB binding and transactivation in human brain endothelial cells. J Neurosci Res 66: 583-591.

Mazarakou G, Georgoussi Z (2005). STAT5A interacts with and is phosphorylated upon activation of the mu-opioid receptor. J Neurochem 93: 918-931.

Mennicken F, Maki R, de Souza EB, Quirion R (1999). Chemokines and chemokine receptors in the CNS: a possible role in neuroinflammation and patterning. Trends Pharmacol Sci 20: 73-78.

Miyatake M, Narita M, Shibasaki M, Nakamura A, Suzuki T (2005). Glutamatergic neurotransmission and protein kinase $\mathrm{C}$ play a role in neuron-glia communication during the development of methamphetamine-induced psychological dependence. Eur $J$ Neurosci 22: 1476-1488.

Narita M, Funada M, Suzuki T (2001). Regulations of opioid dependence by opioid receptor types. Pharmacol Ther 89: 1-15.

Narita M, Miyatake M, Shibasaki M, Tsuda M, Koizumi S, Narita M et al (2005a). Long-lasting change in brain dynamics induced by methamphetamine: enhancement of protein kinase C-dependent astrocytic response and behavioral sensitization. J Neurochem 93: 1383-1392.

Narita M, Shibasaki M, Nagumo Y, Narita M, Yajima Y, Suzuki T (2005b). Implication of cyclin-dependent kinase 5 in the development of psychological dependence on and behavioral sensitization to morphine. J Neurochem 93: 1463-1468.

Nestler EJ (2001). Molecular basis of long-term plasticity underlying addiction. Nat Rev Neurosci 2: 119-128.

Paxinos G, Franklin KBJ (1997). The Mouse Brain in Stereotaxic Coordinates. Academic Press: San Diego.

Raghavendra V, Tanga FY, DeLeo JA (2004). Attenuation of morphine tolerance, withdrawal-induced hyperalgesia, and associated spinal inflammatory immune responses by propentofylline in rats. Neuropsychopharmacology 29: 327-334.

Raivich G, Bohatschek M, Kloss CU, Werner A, Jones LL, Kreutzberg GW (1999). Neuroglial activation repertoire in the injured brain: graded response, molecular mechanisms and cues to physiological function. Brain Res Rev 30: 77-105.

Retaux S, Trovero F, Besson MJ (1994). Role of dopamine in the plasticity of glutamic acid decarboxylase messenger RNA in the rat frontal cortex and the nucleus accumbens. Eur J Neurosci 6: $1782-1791$.
Ryan AS, Nicklas BJ (2004). Reductions in plasma cytokine levels with weight loss improve insulin sensitivity in overweight and obese postmenopausal women. Diabet Care 27: 1699-1705.

Schubert P, Ogata T, Rudolphi K, Marchini C, McRae A, Ferroni S (1997). Support of homeostatic glial cell signaling: a novel therapeutic approach by propentofylline. Ann NY Acad Sci 826: 337-347.

Self DW (2004). Regulation of drug-taking and -seeking behaviors by neuroadaptations in the mesolimbic dopamine system. Neuropharmacology 47: 242-255.

Shao Y, Enkvist MO, McCarthy KD (1994). Glutamate blocks astroglial stellation: effect of glutamate uptake and volume changes. Glia 11: 1-10.

Shippenberg TS, Herz A, Spanagel R, Bals-Kubik R, Stein C (1992). Conditioning of opioid reinforcement: neuroanatomical and neurochemical substrates. Ann NY Acad Sci 654: 347-356.

Sriram K, Benkovic SA, Herbet MA, Miller DB, O'Callaghan JP (2004). Induction of gp130-related cytokines and activation of JAK2/STAT3 pathway in astrocytes precedes up-regulation of glial fibrillary acidic protein in the 1-methyl-4-phenyl-1,2,3,6tetrahydropyridine model of neurodegeneration: key signaling pathway for astrogliosis in vivo? J Biol Chem 279: 19936-19947.

Stiene-Martin A, Zhou R, Hauser KF (1998). Regional, developmental, and cell cycle-dependent differences in $\mu, \delta$, and $\kappa$-opioid receptor expression among cultured mouse astrocytes. Glia 22: 249-259.

Suzuki T, Funada M, Narita M, Misawa M, Nagase H (1991). Pertussis toxin abolishes $\mu$ - and $\delta$-opioid agonist-induced place preference. Eur J Pharmacol 205: 85-88.

Sweitzer SM, Schubert P, DeLeo JA (2001). Propentofylline, a glial modulating agent, exhibits antiallodynic properties in a rat model of neuropathic pain. J Pharmacol Exp Ther 297: 12101217.

Thomas DM, Francescutti-Verbeem DM, Liu X, Kuhn DM (2004). Identification of differentially regulated transcripts in mouse striatum following methamphetamine treatment - an oligonucleotide microarray approach. J Neurochem 88: 380-393.

Ullian EM, Christopherson KS, Barres BA (2004). Role for glia in synaptogenesis. Glia 47: 209-216.

Vesce S, Bezzi P, Volterra A (2001). Synaptic transmission with the glia. News Physiol Sci 16: 178-184.

Wise RA, Hoffman DC (1992). Localization of drug reward mechanisms by intracranial injections. Synapse 10: 247-263.

Won CL, Oh YS (2000). cAMP-induced stellation in primary astrocyte cultures with regional heterogeneity. Brain Res 887: 250-258.

Yuen JW, So IY, Kam AY, Wong YH (2004). Regulation of STAT3 by mu-opioid receptors in human neuroblastoma SH-SY5Y cells. Neuroreport 15: 1431-1435. 